\title{
Contribuições da formação doutoral para a construção da identidade docente ${ }^{1}$
}

\author{
Nadia Magalhaes da Silva Freitas ${ }^{2}$ \\ Josyane Barros Abreu ${ }^{3}$
}

\begin{abstract}
RESUMO
Objetivamos apreender as contribuições da formação doutoral para a construção da identidade docente. Na pesquisa, de natureza qualitativa, realizamos entrevista estruturada, modalidade projetiva, junto a docentes, egressos de um programa de doutorado, lançando dois questionamentos, a saber: como você identifica o/a professor(a) que é/tem sido? Que contribuições a experiência doutoral forneceu para essa identificação? Os dados constituídos foram analisados mediante Análise Textual Discursiva. Os docentes manifestaram dificuldades para auto identificar-se, configurando um movimento que intitulamos de problematização de si. Dentre as contribuições do doutorado, para a tecitura da identidade profissional docente, destacamos as seguintes: reconhecer-se insuficiente, constituição de um professor que reflete na/e sobre a prática docente, postura de um professor investigativo etc. Entendemos que a vivencia doutoral representa campo fértil para o desenvolvimento profissional docente, na medida em que protagoniza uma destruição criadora de sua identidade, podendo superar antigas formas de professorar para, então, substituí-las por outras mais inovadoras.
\end{abstract}

PALAVRAS-CHAVE: Formação Doutoral. Identidade Docente. Problematização de si.

\footnotetext{
${ }^{1}$ Trabalho fruto de estudos e pesquisas desenvolvidos na disciplina "Identidade Docente", no período de 2017-2018, do Programa de Pós-Graduação em Educação em Ciências e Matemáticas, da Universidade Federal do Pará, conduzida pelo Prof. Dr. Tadeu Oliver Gonçalves.

2 Doutora. Universidade Federal do Pará, Belém, Pará, Brasil. https://orcid.org/0000-0003-0042-8640. nadiamsf@yahoo.com.br.

3 Mestra. Universidade Federal do Pará, Belém, Pará, Brasil. https://orcid.org/0000-0002-5479-3531. josyanebarros@gmail.com.
} 
Contributions of doctoral training for the construction of teaching identity

\begin{abstract}
We aim to apprehend the contributions of the doctoral training for the construction of the teaching identity. In the research, of a qualitative nature, we conducted a structured interview, a projective modality, with teachers, graduates of a doctorate program, making two questions, namely: how do you identify the teacher who is/has been? What contributions did the doctoral experience provide for this identification? The data were analyzed by Discursive Textual Analysis. Teachers expressed difficulties in self-identification, configuring a movement that we call problematization of self. Among the contributions of the doctorate, for the framing of professional teacher identity, we emphasize the following: recognize insufficient, constitution of a teacher that reflects in/ and on the teaching practice, posture of a research teacher etc. We understand that the doctoral experience represents a fertile field for the professional development of teachers, as it leads to a creative destruction of their identity, being able to overcome old ways of teaching and then replace them with more innovative ones.
\end{abstract}

KEYWORDS: Doctoral Training. Teaching Identity. Problematization of self.

\title{
Introdução
}

Com o advento do século XXI e suas tecnologias da informação, muitas interrogações emergiram quanto ao ofício do professor. Seria ele substituído pelo computador? Seria a docência uma profissão necessária a esse tempo? Estamos caminhando para a extinção da profissão docente? Refletindo sobre questões como essas, Gadotti (2011) discorre sobre a possibilidade de um velho professor estar desaparecendo; mas, nesse processo, não é a docência 
sucumbindo, é a profissão renascendo, transformando-se e, nesta metamorfose, um novo professor está surgindo. Fruto disso, é a professoralidade adquirindo uma nova identidade.

Mas para quê falar de identidade, notadamente a do professor? Pensamos, que partindo de discussões como essas poderemos nos aproximar das novas gerações de professores, capazes de enfrentar as exigências formativas ${ }^{4}$ postas pela diversidade, modernidade e liquidez do mundo atual. Compreender ou ao menos buscar compreensão, como é tecida a identidade do sujeito que ensina, permite-nos olhar com menos julgamento e mais criticidade as dimensões do ato de ensinar (social, psíquica, familiar, política etc) e de formar quem ensina. Ademais, acreditamos, assim como Faria e Souza (2011), que a compreensão que o professor tem de si, enquanto profissional, interfere em sua prática pedagógica e nas relações construídas com seus pares no ambiente escolar. Desse modo, a identidade docente merece atenção nos estudos da área.

Falando em formar quem ensina, é no contexto da formação inicial, continuada e autoformação que acreditamos ser latente a configuração da identidade profissional do professor, visto que nelas o sujeito tem acesso à cultura profissional, podendo (re)construir, entre pares, competências, habilidades, valores e atitudes do ofício, mobilizados por questões subjetivas, ou não, da profissão.

Tratando de formação inicial e continuada, Pimenta (2002) chama atenção para o fato destas terem contribuído pouco para a construção de uma nova identidade profissional docente, por ainda seguirem um currículo formal marcado pela ausência do diálogo entre a tríade conteúdos, atividades docentes e realidade das escolas. Fato é que, ainda estamos presos às tradições formativas e acabamos reproduzindo currículos e práticas, seguindo

\footnotetext{
${ }^{4}$ Capacidade de aprender a aprender consigo e com o outro, competência para saber agir na sala de aula diante das diversidades apresentadas, habilidades comunicativas, domínio da linguagem informacional e dos meios de informação, habilidades de articular o conhecimento em rede.
} 
receitas de como formar um "bom professor", como se tivéssemos controle e garantia das identidades que estão sendo construídas.

Mesmo o doutoramento sendo um curso de formação continuada, acreditamos que este tem potencial para não se enquadrar no comentário da autora. Ademais, conjecturamos que ele alça voos bem mais altos ao buscar, ao longo de aproximadamente quatro anos, desenvolver nos doutorandos autonomia para refletirem, de modo a redimensionarem suas práticas, desgarrada de um currículo petrificado e anacrônico. Desse modo, julgamos ser o doutorado uma experiência propícia para a gestação de uma professoralidade diferenciada, cuja formação identitária seja tão dinâmica e líquida quanto os desafios educativos dos dias de hoje.

Mas o que entendemos por professoralidade diferenciada? Apostamos na identidade de um sujeito inquieto e insatisfeito com status quo do modus operandi da educação, o qual busca refletir para mudar e superar realidades, movimentando-se em direção de um (re)inventar-se como professor, a fim de inovar o ensino e a aprendizagem. Atentamos que a inovação entendida por nós se aproxima da concepção de Farias (2006, p. 43), qual seja, “[...] definida como estratégias que expressam dinâmicas explícitas com intenção de alterar ideias, concepções, conteúdos e práticas em alguma direção renovadora em relação a existente", podendo ser abandonada ou cancelada se assim for necessário.

É apostando nisso, que a pesquisa, ora relatada, segue questionando sobre em que aspectos o doutoramento tem contribuído para construção da identidade docente? Interrogando ainda se tais contribuições têm potencialidades para a constituição de uma professoralidade diferenciada? Nesse sentido, objetivamos apreender as contribuições da formação doutoral, vividas numa pós-graduação, para a construção da identidade docente.

\section{Compreensões sobre identidade docente}


A literatura nos mostra que as discussões sobre identidade têm sido múltiplas, passando pelas áreas da psicologia, sociologia, história, filosofia e pedagogia (CIAMPA, 1987; DUBAR, 2009; HALL, 2006; BAUMAN, 2005; PIMENTA, 2002). Diante de tal diversidade, a identidade, como objeto de estudo, vem ganhando significados diversos e, por vezes, antagônicos. Nesse sentido, acreditamos ser importante esclarecer que identidade estamos falando e, para isso, apoiamo-nos, principalmente, nas compreensões dos conceitos de Dubar (2009), o qual trata identidade em seu aspecto geral e Pimenta (2000), que se refere a identidade do professor.

Claude Dubar, nascido na França, é professor de sociologia da Universidade de Versailles, e é um dos nomes mais citados sobre o tema em questão (OLIVEIRA; GOMES, 2004). No livro "A crise das identidades: a interpretação de uma mutação", Dubar (2009) relata fenômenos que interferem direta e indiretamente nas formas identitárias, isso num contexto francês, mas que é plenamente coerente com o cenário brasileiro. Para ele, perturbações vividas nas relações familiares, políticas, amorosas, profissionais e simbólicas são significativas para a constituição do sujeito, e podem ser indissociáveis para o reconhecimento de si.

A mutação interpretada pelo autor trata do movimento de um conjunto de processos em interação e seu momento histórico, o qual contempla as mais diversas questões que atravessam a vida do sujeito, desde as questões profissionais até as da vida privada e/ou simbólica ${ }^{5}$. Tal mutação se dá por meio de crises, as quais (re)configuram a identidade pessoal num processo incerto e, às vezes, dramático, mas que pode ser emancipador, visto que para Dubar (2009, p.185), é "[...] a crise que revela o sujeito a ele próprio, o obriga a refletir, a mudar, a lutar para superar e a inventar-se a si próprio, com os outros". É no movimento de "inventar-se a si próprio" que vislumbramos a esperança da professoralidade adquirir uma nova identidade, a qual tenha

\footnotetext{
${ }^{5}$ Compreendido pelo autor como crenças e práticas religiosas e também ideológicas
} 
potencial para dar conta das novas exigências formativas, pautada na complexidade e integralidade de saberes.

Assim, Dubar (2009) compreende identidade como sendo resultado duma dupla operação: diferenciação - à qual a identidade é a diferença-, e; generalização - a identidade é a pertença comum de classes. Nesse sentido, o autor trata a identidade como sendo um paradoxo: aquilo que existe de único e aquilo que é partilhado. Assim, são várias as identificações assumidas por nós, num processo dinâmico, subjetivo, indefinido e permanente no decorrer da nossa história de vida.

No que refere à docência, Farias e Souza (2011) fazem um levantamento das pesquisas no campo da formação de professores e percebem que são escassas as discussões que abordam a identidade do professor como objeto de estudo. E mais: quando abordada, muitas vezes o é de maneira superficial, que pouco contribui para o aprofundamento dos estudos. Diante disso, vemos em Dubar (2009) um referencial consistente para compreender, primeiramente, as identidades profissionais, de modo geral, não especificamente a do professor, as quais são entendidas no sentido da configuração Eu-Nós6, sendo "[...] maneiras socialmente reconhecidas para os indivíduos se identificarem uns aos outros, no campo do trabalho e do emprego" (DUBAR, 2009, p. 85).

Desse modo, para compreender melhor a identidade do professor aqui neste trabalho, recorremos a Pimenta (2005), a qual relaciona a identidade do professor aos saberes da docência ${ }^{7}$, sendo a mobilização dos saberes da experiência o primeiro passo para mediar o processo desta construção. $\mathrm{O}$ segundo passo, trata da significação dos saberes do conhecimento, no sentido de conteúdos específicos das ciências; e o terceiro, diz respeito aos saberes pedagógicos, num sentido de reinventar a didática, distanciando-a da tradição. Toda essa construção deve se dar num processo de reflexão que a

\footnotetext{
${ }^{6} \mathrm{O}$ autor trata no sentido de que não há não há identidade do Eu sem a identidade do Nós; Eu me reconheço quando reconheço o outro.

${ }^{7}$ Constituído por outros saberes que para Pimenta são: saberes da experiência, saberes do conhecimento e os saberes pedagógicos.
} 
autora considera uma proposta metodológica para a construção de uma nova/outra identidade docente: refletir na ação, sobre a ação e sobre a reflexão na ação.

Em suma, a identidade do professor, aqui tratada, é compreendida como sendo um processo dinâmico e subjetivo da construção do sujeito historicamente situado, na configuração de uma metamorfose das relações vividas nos mais diversos campos (familiar, amoroso, político, religioso, profissional), mobilizados ainda pelos saberes da docência (DUBAR, 2004; PIMENTA, 2002).

\section{Desenho metodológico da pesquisa}

A pesquisa foi realizada em consonância com princípios da abordagem qualitativa, cujas possibilidades referem-se à compreensão da realidade e do mundo dos significados, sem a pretensão de quantificar sujeitos e opiniões; tal abordagem possibilita a apreensão dos significados, das aspirações, das crenças e dos valores dos sujeitos envolvidos (MINAYO, 2016). Como estratégia de recolha de dados, optamos pela entrevista estruturada, notadamente na modalidade projetiva. Assim, lançamos aos sujeitos a compreensão de Dubar (2004) e Pimenta (2000) sobre a identidade do professor, inclusive, já mencionado no final da seção anterior. A perspectiva era que tal compreensão se constituísse “[...] um convite ao entrevistado para discorrer sobre o que [...] lê" (MINAYO, 2016, p. 59).

O contexto da entrevista se deu no espaço virtual, numa ferramenta de comunicação instantânea ${ }^{8}$, organizada de forma assíncrona, na qual as perguntas foram enviadas aos participantes e os mesmos responderam quando melhor lhes convieram (FLICK, 2009). As questões lançadas foram as

\footnotetext{
${ }^{8}$ WhatsApp Messenger, aplicativo multiplataforma de mensagens instantâneas e chamadas.
} 
seguintes: Como você identifica o/a professor(a) que é/tem sido? Que contribuições a experiência doutoral forneceu para essa identificação?

Os sujeitos envolvidos foram cinco egressos, do doutorado do Programa de Pós-Graduação em Educação em Ciências e Matemáticas (PPGCEM) ${ }^{9}$, da Universidade Federal do Pará (UFPA). A escolha pela formação continuada como campo de investigação justifica-se por compreendermos, assim como Lacerda e Melo, (2017, p. 439) que "[...] constitui-se como alicerce para as alterações nas práticas pedagógicas dos professores, pois, ao terem oportunidade de investigar e refletir sobre sua docência [...] poderão rever suas opções teórico-metodológicas."

A seleção dos sujeitos deu-se por acessibilidade. Os participantes são hoje professores, sendo quatro atuantes no nível superior, formadores de professores, e um no nível básico de ensino da rede pública (ensino médio). Os mesmos convergem para o campo das ciências (Física, Biologia e Ciências Naturais) na formação inicial e também doutoral. Esses sujeitos são mencionados no texto com nomes fictícios, na intenção de mantê-los em anonimato.

Diante das respostas obtidas, os dados foram organizados e analisados mediante Análise Textual Discursiva (ATD). Para Moraes (2007, p. 87), tal estratégia de análise de dados "[...] trabalha com textos, podendo partir de materiais já existentes ou esses podem ser produzidos dentro da própria pesquisa", tendo como intensão a produção de novas compreensões sobre os fenômenos e discursos investigados (MORAES, GALIAZZI, 2011). Cumpre destacar, que o "[...] conjunto de textos submetidos à análise costuma ser denominado corpus [...] [o que corresponde a uma] multiplicidade de vozes se manifestando sobre os fenômenos investigados" (MORAES, 2007, p. 87). É do corpus que elementos significativos foram utilizados na elaboração de um novo texto - metatexto, com a finalidade de apresentar os resultados das

\footnotetext{
${ }^{9}$ O PPGECM visa oferecer aos graduados e formadores de professores das áreas de Ciências (Física, Química e Biologia), Matemática, Educação Ambiental e áreas afins, oportunidade de estudos e pesquisas sobre os fundamentos atuais do ensino e pesquisa na área de Ensino de Ciências e Matemáticas (Área 46 da CAPES).
} 
análises. A triangulação dos dados nos permitiu estabelecer categorias emergentes, as quais intitulam as seções que se seguem.

\section{Professoralidade em movimento: da problematização para a leitura de si}

A priori, falar de si parece algo simples, mas quando a questão é a interpretação de si, a dificuldade emerge. Isso porque, o exercício de autoidentificar-se não é uma questão de fácil resolução, como aponta Sarraf (2017). Atribuímos a essa dificuldade a dinâmica contingência das formas identitárias que compõem o Eu. Nesse sentido, concordamos com Dubar (2009, p.178) ao conjecturar que a

[...] partir do momento que a situação muda, esta maneira de falar de si pode modificar-se. A identidade pessoal é um processo, uma história, uma aventura, e nada permite que ela se fixe num qualquer momento da biografia.

Para Dubar (2009), a autoidentificação é compreendida como identidade narrativa, que nada mais é que a verbalização do sujeito de si, duma construção subjetiva da sua história, no que diz respeito as suas experiências significantes (profissional, política, religiosa, amorosa, cultural etc.). No entanto, “[...] determinar uma certa configuração das formas identitárias, por meio de várias produções linguísticas duma pessoa, não é defini-la enquanto sujeito, impondo-lhe uma etiqueta, seja ela qual for" (DUBAR, 2009, p.178). Até porque, a interpretação de si é um enigma por decifrar, num movimento incerto, temporário e inacabado.

$\mathrm{Na}$ intenção de compreender a leitura que os sujeitos fazem de si, solicitamos que os mesmos se manifestassem sobre como se identificam o/a professor(a) que são/tem sido. E a fala da professora Dayane retrata a dificuldade em se definir, nos seguintes termos: 
Hoje minha percepção sobre a minha identidade é muito turva, não consigo apresentar uma definição clara, pois continuamente me percebo refletindo e tecendo críticas a minha prática docente, estou permanentemente aberta ao novo. Apesar da dificuldade em descrever minha identidade, me reconheço como uma professora melhor do que eu era no começo do exercício do magistério. (Professora Dayane)

Apesar dos impasses relacionados à autoidentificação, reconhecemos nesse exercício um potencial significativo para a construção de uma professoralidade diferenciada, que é a problematização de si, no sentido do professor que sou/tenho sido. Conjecturamos que tal problematização serve como um convite à reflexão e à análise crítica de nossas ações, podendo provocar o questionamento do que está posto, daquilo em que se acredita e do que faz na docência, exercício este explícito na fala da Professora Dayane.

Outro ponto que valoriza tal problematização no processo de construção de uma nova/outra professoralidade fundamenta-se em Pimenta (2002), ao julgar a mobilização dos saberes da experiência ${ }^{10}$ como o primeiro passo para mediar o processo de construção da identidade do professor e, também, em Abreu e Freitas (2017, p. 18), ao argumentar que a problematização destes saberes colabora para a edificação de conhecimentos "[...] necessários a uma reconstrução teórica, didática e epistemológica do fazer e do ser professor nos tempos de hoje".

Apostamos que a problematização de si, do sujeito que ensina, tem como intencionalidade causar crises e rupturas na identidade do professor, com a finalidade de despertar o interesse e a possibilidade de mudar, de se transformar, ou como diz a Professora Dayane, de estar "permanentemente aberta ao novo". E nesse movimento, torna-se mais perceptível à dinâmica e

\footnotetext{
${ }^{10}$ Saberes construídos, ainda quando alunos, os quais aprenderam e aprendem a ser professor, herdando hábitos, valores e atitudes docentes.
} 
à temporalidade das identidades, despertando no sujeito o sentimento de inacabamento, como mencionam as professoras, a saber:

\section{[...] não considero que minha identidade como docente esteja acabada (Professora Neide, destaque do autora);}

Ser professora me parece algo que sempre fez parte da minha identidade, [...] acredito no professor como um sujeito em construção, que aprende, que constrói e que se reconstrói na interação com os outros (Professora Eliana).

Reconhecer-se como inacabado é um passo importante na leitura de si, e como diz Cortela (2016), "nascemos não prontos e vamos nos fazendo", e como qualquer outro ser humano, o ser professor deve estar continuamente se (re) fazendo (FARIAS, 2012), num processo em que não há completude. Esse reconhecimento é fundamental para o processo de se fazer e de ser professor, já que conscientes do inacabamento, podemos ir mais além nessa construção (FREIRE, 2009) e reconstrução, como pontua a Professora Eliana.

Fato é que, mesmo enquanto professores, somos eternos aprendentes. E o sentimento de insuficiência não é uma fragilidade da profissão, pelo contrário, é uma qualidade que pode enveredar-nos por percursos identitários diferentes, quem sabe, mais criativos e inovadores, os quais nos permitam mudar e romper com hábitos e atitudes enraizados na tradição.

No movimento da interpretação de si, emerge de forma significativa a identificação como um professor reflexivo, como mostram os seguintes excertos:

Creio que me considero um professor reflexivo, que reflete a ação docente constantemente [...] ainda que haja, eventualmente, um conflito interior entre o antigo e tradicional professor que eu era, ou ainda sou, e o atual professor que tenho procurado ser ou desejo ser. [...]. Mas esse processo de buscar ser um professor mais reflexivo 
não foi algo que aconteceu como num passe de mágica, mais em um processo permeado de desvelamentos e incômodos (Professor Alex);

$\mathrm{Na}$ verdade eu tenho aprendido a ser professora, e nesse aprender a ser professora eu me vejo como uma pessoa que estuda que tenta, na medida do possível, analisar e refletir sobre a minha prática [...]. Então a professora que eu busco ser, e que acho que tenho conseguido ser, é a professora que, não digo reflexiva porque as vezes é impossível você refletir num ambiente de trabalho que você tem uma carga horária muito extensa, mas eu busco dentro do possível esta reflexão (Professora Silvana).

A reflexão na e sobre a prática do professor, constitui-se caminho necessário para a construção de uma identidade capaz de superar impasses da prática profissional docente. Tais impasses se configuram como situações complexas e exigem resoluções "[...] num terreno de grande complexidade, incerteza, singularidade e de conflito de valores" (PIMENTA, 2002, p. 30). Desse modo, o desejo e a busca que movem o sujeito na construção de um professor reflexivo tornam-se característicos de uma professoralidade distinta, mostrando-nos que estamos num caminho próximo.

\section{Contribuições da formação doutoral para a construção da identidade docente}

Como uma formação stricto sensu, o doutorado tem por objetivo "[...] desenvolver e aprofundar, pela via da pesquisa, a formação adquirida na graduação (SOARES; CUNHA, 2010, p. 41)". Assim, o doutoramento tem como elemento basilar a articulação entre pesquisa e docência, sem hierarquia, objetivando formar professores pesquisadores, em especial, docentes universitários. Tal formação deve seguir caminhos na direção da 
tecitura de uma identidade profissional mais autônoma, crítica e comprometida com a transformação social imprescindível ao tempo presente.

Essa formação busca "[...] apresentar, discutir, refletir e construir elementos que subsidiem uma prática social complexa: a docência no ensino superior. Trata-se de um início formal da edificação de uma identidade docente" (LOURENÇO; LIMA; NARCISO, p.700, 2016). Assim sendo, consideramos que a identificação de si, enquanto professor, contada pelos sujeitos na seção anterior, também é produto de uma construção acadêmica, vivida desde a graduação até o doutorado. No entanto, acreditamos que predicados como a reflexão e o sentimento de inacabamento, reconhecidos pelos professores anteriormente, são frutos emancipados na experiência doutoral, visto a complexidade intelectual de saberes e de práticas da professoralidade cultivados nesta formação.

Além desses predicados, os docentes egressos do doutorado manifestaram outras contribuições da formação doutoral para a constituição da identidade dos professores que são/tem sido. Nesse sentido, Pimenta (2002) coloca que o processo de construção do sujeito emerge como resposta a necessidades que estão postas pelas sociedades. Desse modo, as contribuições do doutoramento evidenciadas pelos sujeitos, podem ser efeitos de inquietações do cenário educacional, na sua maioria, impregnado por práticas professorais engessadas, currículos anacrônicos e disciplinas científicas que pouco ou nada têm de encantadoras aos olhos de nossos alunos (KRASILCHIK, 2000).

As falas das professoras mencionam a importância da experiência doutoral para a tecitura de si, a saber:

As experiências que vivi durante o processo de doutorado foram determinantes para a construção da pessoa que eu sou, assim como para minha projeção profissional, pois grande parte do que sou devo as experiências vividas e compartilhadas, quer sejam no grupo de estudo quer sejam nos projetos de ensino, pesquisa e/ou extensão. 
Experiências estas que me fazem cada dia mais apaixonada pelo que faço e pelo que estar por vir (Professora Eliana);

A experiência doutoral enriqueceu minha visão de mundo e minha prática docente Consequentemente, alterou minha forma de interação com os meus alunos e com outros professores. $\mathrm{O}$ doutorado me fez acrescentar de forma acentuada uma característica importante a minha identidade docente: a humildade. Percebi a importância de deixar que o outro se aproxime e interaja para que possamos trocar saberes sem hierarquia [...] me fez perceber o quanto eu desconheço o mundo e o quanto há de novo para se aprender [...] (Professora Dayane);

Entendo que durante o doutorando iniciei uma nova construção da minha identidade docente na medida em que passei a compreeender a complexidade do ser professor para além de saber conteúdos e metodologias (Professora Neide).

Consideramos que as experiências protagonizadas pelos sujeitos no doutorado, configuram-se valorosas por constituir uma formação que prioriza a construção de identidades profissionais, nos termos de Pimenta (2002), a saber: partir da significação social da profissão, da revisão constante destes significados, da revisão das tradições, da reafirmação constante de práticas consagradas culturalmente e que permanecem significativas, do confronto entre teorias e práticas, da análise sistemática das práticas à luz das teorias existentes, do significado que cada professor confere à atividade docente e das relações que tecem com seus pares.

A professora Dayane destaca a humildade como característica construída no doutorado, enfatizando o quanto ela é relevante para "[...] deixar que o outro se aproxime e interaja para que possamos trocar saberes sem hierarquia [...]". Parece uma questão simples, mas se olharmos para além dos dedos reconheceremos que a ação de ensinar, por vezes é hierárquica, 
sendo o professor ainda rotulado como o detentor do conhecimento e dono da verdade. E o doutoramento hoje, na área da educação e/ou ensino, tem potencial para desconstruir rótulos como esses, pela criticidade dada às discussões cultivadas nesse contexto.

Reconhecer-se humilde enquanto professor é compreender que nosso aluno não aprende apenas com a nossa fala, mas também com a fala do outro; e mais: é enfatizar que nós, professores, aprendemos com a fala deles (FREIRE, 2009). A "troca de saberes sem hierarquia" mencionada pela professora, reflete na nossa prática docente, na qual cultivando essa ideia, podemos priorizar planejamentos de situações didáticas que rescindam o monólogo e valorizem o diálogo no processo de ensino e de aprendizagem.

Outra contribuição que emerge nas manifestações dos sujeitos é a tecitura de um professor pesquisador, característica resultante da própria natureza do doutorado, o qual busca envolver os sujeitos em processos e procedimentos da investigação científica ao longo de toda formação. Nesse sentido, Lourenço, Lima e Narciso (2016) apontam que os cursos stricto senso (mestrado e doutorado), têm seguido perspectivas demasiadamente técnicas no que tange à pesquisa, sobrepondo à docência. No entanto, o que se evidencia nas falas dos professores aqui não é a investigação específica ao campo científico em si, mas também sua própria prática na sala de aula, nos seguintes termos:

A experiência doutoral [...] serviu para [...] confirmar que eu como professora posso sim ser pesquisadora. E que não é só pegar um tema e levar para os meus alunos e perguntar o que eles entendem ou não entendem sobre esse tema e fazer um artigo. Então, o doutorado ele veio confirmar, ele veio dizer assim, olha tu tens agora muita coisa que estudar, mas tu podes pesquisar, tens que contribuir tanto no ensino como quanto na pesquisa, tu tens que te movimentar [...] (Professora Silvana) 
O doutorado foi um processo de amadurecimento profissional na direção de aperfeiçoar o docente que sou no sentido de ser um professor pesquisador, alguém capaz de vislumbrar que o espaço de ensino como a sala de aula, os espaços não formais e etc. podem potencialmente ser um local de pesquisa (Professor Alex).

A exploração da prática docente como lócus de pesquisa possibilita a construção de conhecimentos sobre os problemas profissionais visando criar e inovar a prática do docente. Nessa perspectiva, Bortoni-Ricardo (2008, p. 46) reconhece que o professor pesquisador se diferencia dos demais por assumir o “[...] compromisso de refletir sobre a sua própria prática, buscando reforçar e desenvolver aspectos positivos e superar as próprias deficiências. Para isso ele se mantem aberto a novas ideias e estratégias [...]”.

A pesquisa é um elemento significativo para o exercício de uma professoralidade diferenciada por propiciar a reflexão na ação e sobre a ação, permitindo que o professor repense o seu trabalho, superando obstáculos e impasses da profissão. Ademais, vemos no professor que investiga o seu contexto de trabalho, atitudes que o aproximam de elementos importantes da docência, tais como "[...] a problematização, a intencionalidade para encontrar soluções, a experimentação metodológica, o enfrentamento de situações de ensino complexas, as tentativas "[...] de uma didática inovadora, que ainda não está configurada teoricamente" (PIMENTA, 2000, p.37).

Nesse sentido, apostamos que "[...] vislumbrar o espaço de ensino como a sala de aula" para o exercício da pesquisa, como coloca o professor Alex, permite ainda a ação do que já pontuamos aqui, que é a problematização de si. No instante que o professor investiga seu contexto em sala de aula, ele tem a oportunidade de refletir sua prática docente, questionando o professor que é/tem sido, no ímpeto de crescer profissionalmente, lapidando habilidades, atitudes, significados e sentidos da sua função presente e futura como professor. Direcionando assim, mesmo que temporária e transitória, uma 
nova identidade profissional docente, coerente com que aponta Pimenta (2002).

A pesquisa serve como elemento de estímulo para o próprio desenvolvimento profissional do professor, universitário ou não, redimensionando "[...] a prática e as teorias do docente, revitalizando e produzindo os saberes da ação pedagógica" (GONÇALVES, 2006, p. 56), saberes estes que configuram a identidade profissional do sujeito que ensina. Além do mais, ela pode ser um elemento de transformação do "agir profissional do professorado" que se constrói como parte de uma nova identidade profissional (NUÑEZ; RAMALHO, 2005, p. 89).

\section{Notas para refletir questões sobre a identidade docente}

Assim como a mutação das identidades defendidas por Dubar (2009), as questões apresentadas e discutidas neste artigo são dinâmicas, fluidas e até provisórias. Dessa forma, entendemo-las como provocações para discussões iniciais sobre as contribuições da formação doutoral para a configuração da identidade docente, na perspectiva de uma nova/outra professoralidade, fomentadora do debate da diversidade de ideias, valores, culturas, estimuladora da curiosidade e da criatividade dos envolvidos, além das potencialidades para a construção de saberes dinâmicos e interligados.

As contribuições manifestadas pelos professores mostram-se valiosos para a dinâmica e subjetiva transformação identitária na direção de nova/outra professoralidade. Não obstante, pensamos que a referida transformação tem no doutoramento campo fértil para o desenvolvimento profissional docente por, fundamentalmente, permitir que os sujeitos protagonizem uma destruição criadora de sua identidade, podendo superar antigas formas de professorar para, então, substituí-las por outras mais inovadoras. 
Os resultados mostram que os sujeitos apresentam dificuldades para autoidentificar-se, configurando um movimento que intitulamos a problematização de si, o qual, mobilizados pela dúvida e incerteza, olham com mais criticidade e reflexão para o professor que são/tem sido, o que pode despertar nos professores o interesse e a possibilidade de mudar, de se transformar, na direção de "inventar-se a si próprio", como coloca Dubar (2009). Quanto às contribuições do doutorado para a tecitura da identidade profissional docente, os sujeitos apontam: reconhecer-se insuficiente, humilde diante do processo de construção do conhecimento junto o alunado (superando hierarquias do conhecimento), a constituição de um professor que reflete na e sobre a prática docente e, principalmente, a postura de um professor investigativo, que a investigação contribui tanto para o ensino como para a pesquisa da área.

Por fim, enxergamos na formação doutoral contribuições com potencial para a tecitura de si enquanto professor, no sentido de constituir-se um professor inovador, cuja identidade - tanto pessoal quanto profissional - é esculpida no movimento permanentemente dinâmico.

\section{Referências}

ABREU, J. B; FREITAS, N. M. da S. Proposições de inovação didática na perspectiva dos Três Momentos Pedagógicos: tensões de um processo formativo. Ensaio Pesquisa em Educação em Ciências. n.19, e.2734, 2017. Disponível em:

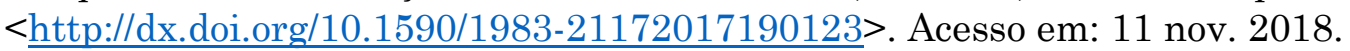

BAUMAN, Z. Identidade: entrevista a Benedetto Vecchi. Rio de Janeiro: Jorge Zahar, 2005.

BORTONI-RICARDO, S. M. O professor pesquisador: introdução à pesquisa qualitativa. São Paulo: Parábola. (Série Estratégias de Ensino, n. 8). 2008.

CIAMPA, A. C. A estória do Severino e a História da Severina. São Paulo: Editora Brasiliense, 1987.

CORTELLA, M. S. Não nascemos prontos! Provocações filosóficas. Petrópolis, RJ: Vozes, 2016. 
DUBAR, C. A crise das identidades: a interpretação de uma mutação. São Paulo: EDUSP, 2009.

FARIA, E.; SOUZA, V. L. T. de. Sobre o conceito de identidade: apropriações em estudos sobre formação de professores. Revista Semestral da Associação Brasileira de Psicologia Escolar e Educacional, São Paulo, v. 15, n.1, p. 35-42, 2011. http://dx.doi.org/10.1590/S1413-85572011000100004.> Acesso em: 29 nov. 2018.

FARIAS, I. M. S. de. Inovação, mudança \& cultura docente. Brasília: Liber Livros, 2006.

Didática e docência: aprendendo a profissão. Brasília: Liber Livros, 2012. FLICK, U. Introdução à pesquisa qualitativa. Porto Alegre: Artmed, 2009.

FREIRE, P. Pedagogia da autonomia: saberes necessários à prática educativa. 39. Ed. São Paulo: Paz e Terra, 2009.

GADOTTI, M. A boniteza de um sonho: ensinar-e-aprender com sentido. 2. Ed. São Paulo: Editora e Livraria Paulo Freire, 2011.

GONÇALVES, T. O. A Constituição do formador de professores de matemática: a prática formadora. Belém: CEJUP ED, 2006.

HALL, S. A identidade cultural na pós-modernidade. 11. Ed. São Paulo: DP\&A, 2006.

LACERDA, V. L.; MELO, G. F. Formação e desenvolvimento profissional de professoras da Educação Básica. Ensino em Re-Vista, Uberlândia, v. 24, n. 2, p.431450, 2017.

LOURENÇO, C. D. da S.; LIMA, M. C.; NARCISO, E. R. P. Formação pedagógica no ensino superior: o que diz a legislação e a literatura em Educação e Administração? Avaliação, Campinas, Sorocaba, v. 21, n. 3, p. 691-717, 2016. Disponível em: http://dx.doi.org/10.1590/S1414-40772016000300003. Acesso em: 12 set. 2018.

MINAYO, M. C. de S. O desafio da pesquisa social. In: ; DELANDES, S. F.; GOMES, R. (Org.). Pesquisa social: teoria, método e criatividade. 27. Ed. Petrópolis, RJ: Vozes, 2016. p. 9-28.

MORAES, R. Mergulhos discursivos: análise textual qualitativa entendida como processo integrado de aprender, comunicar e interferir em discursos. In: GALIAZZI, M. C.; FREITAS, J. V. Metodologias emergentes de pesquisa em educação ambiental. Ijuí: Unijuí, 2007, p. 85-114.

; GALIAZZI, Maria do Carmo. Analise textual discursiva. Ijuí: Unijuí, 2007.

NUÑEZ, I. B.; RAMALHO, B. L. A pesquisa como recurso da formação e da construção de uma nova identidade docente: notas para uma discussão inicial. ECCOS, São Paulo, v. 7, n. 1, p. 87-111, 2005. Disponível em: 
http://www.comperve.ufrn.br/conteudo/observatorio/arquivos/artigos/pesquisaidentidade-docente.pdf>. Acesso em: 03 set. 2018.

OLIVEIRA, C. A. V. de; GOMES, A. A. Apontamentos sobre o conceito de identidade profissional professores. Série-Estudos. Periódico do Mestrado em Educação da UCDB, Campo Grande, MS: n.18, p.193-202, 2004. Disponível em: http://www.serieestudos.ucdb.br/index.php/serie-estudos/article/view/481>. Acesso em: 12 set. 2018.

PIMENTA, S. G. Formação de professores: identidade e saberes da docência. 4 Ed. In: PIMENTA, S. G (Org.). Saberes pedagógicos e atividade docente, 4 ed. São Paulo: Cortez, 2005. p. 15-34.

Didática e formação de professores: percursos e perspectivas no Brasil e em Portugal. 3 Ed. São Paulo: Cortez, 2000.

SARRAF, I. P. B. Cartografia de professores migrantes: formação docente na construção de identidades. Rio Branco: Nepan, 2017.

Recebido em março de 2019.

Aprovado em novembro de 2019. 